General paper

\title{
High Temperature Fatigue Deformation Measurement of Ceramics Thermally Sprayed SUS304 Steel Using an ESPI System
}

\author{
Rongguang WANG*, Tarou ToKUDA** and Mitsuo KIDO* \\ *Dept. of Mech. Sys. Eng., Fac. of Tech., Hiroshima Institute of Technology, Saeki-ku, Hiroshima, 731-5193 Japan \\ ${ }^{* *}$ Graduate Student, Hiroshima Institute of Technology, Saeki-ku, Hiroshima, 731-5193 Japan
}

\begin{abstract}
Surface strains of $\mathrm{Al}_{2} \mathrm{O}_{3} / \mathrm{NiCr}$ thermally sprayed SUS304 steel specimens during the fatigue test $\left(\sigma_{\max }=173 \mathrm{MPa}, R=0, T=873 \mathrm{~K}\right)$ were measured using an electronic speckle pattern interferometry (ESPI) system. The relationships between surface strain and crack initiation / delamination behavior are discussed.

The strain values obtained from the ESPI system were confirmed to be almost the same as those from strain gauges on un-sprayed specimens when tensile stresses were loaded at 293K. Thermal expansion deformation and stress deformation at high temperatures were easily measured with the ESPI system. The presence of cracks and delamination on the sprayed coatings can be nondestructively detected by analyzing the strain concentration or decrease. The surface strains of sprayed specimens were almost the same as those of un-sprayed specimens at $873 \mathrm{~K}$, indicating that the deformation of the sprayed coatings are always associated with that of the substrate surfaces at high temperature. The maximum surface strain after $1 \times 10^{5}$ cycles test was a little lower than after 2 cycles test. Surface cracks occurred but stopped at the inner NiCr layer after 2 cycles test at $873 \mathrm{~K}$. Many surface cracks and delamination along the interface between the NiCr layer and substrate interface were confirmed after $1 \times 10^{5}$ cycles test.
\end{abstract}

Key words: Alumina ceramics, Thermally spraying coating, Electronic speckle pattern interferometry (ESPI), Fatigue, Strain, Deformation.

\section{INTRODUCTION}

Thermally spraying coated ceramics are usually used as thermal barrier coatings (TBC) because of their high thermal resistance [1]. However, their integrity and reliability might be damaged when the deformation becomes too large. Although many researches [2-17] on the damage behavior of ceramic coatings have been carried out, there are not many published reports [3-7] on the deformation / damage behavior at high temperatures because it is difficult to apply the strain gauge. Particularly, there is almost no research on the nondestructive detection of crack initiation and delamination of thermally sprayed coatings at high temperatures. In order to solve these problems, non-contact measuring methods are necessary.

The electronic speckle pattern interferometry (ESPI) [18-21] method is one effective way to measure deformation without contacting the specimen. Although this method has been successfully applied at room temperature, its application at high temperatures has not been closely studied. Ogura et al [3-7] have measured the fatigue strain within an area of $1 \mathrm{~mm}$ diameter on a ceramics sprayed material at high temperature using a SSDG method similar to the ESPI method, in which a laser beam of $1 \mathrm{~mm}$ diameter was illuminated on specimen surfaces and laser beam reflections from two directions were detected. On the other hand, the ESPI method used in this work had two laser beams illuminated on specimen surfaces and the deformation within a large area of about $200 \mathrm{~mm} \times 300 \mathrm{~mm}$ can be simultaneously measured.

In this work, fatigue tests were carried out on an
$\mathrm{Al}_{2} \mathrm{O}_{3} / \mathrm{NiCr}$ sprayed $\mathrm{SUS} 304$ stainless steel, and the surface deformation/damage behavior were investigated using the ESPI method. The relationships between the surface deformation and the cracking/delamination of the coatings are discussed.

\section{EXPERIMENTAL DETAILS}

Solution treated SUS304 steel (C: $0.06 \%$, Si: $1.00 \%$, Mn: $2.00 \%$, P: $0.045 \%$, S: $0.030 \%$, Cr: $18.00 \%$, Ni: $8.00 \%, \sigma_{0.2}=290 \mathrm{MPa}$ ) was used as the spraying substrate. The specimen shape is shown in Fig. 1. The atmospheric plasma spraying apparatus (TECHNOSERVE CO., LTD) was used to spray $\mathrm{Al}_{2} \mathrm{O}_{3}$ (outer coating) $/ \mathrm{Ni} 80 \% \mathrm{Cr} 20 \%$ (inner bond coating) coating on the hatching area shown in Fig.1. The spraying conditions are shown in Table1.

Fatigue tests were carried out with the servo pulse fatigue-testing machine (Shimadzu Co.: EHF-EG50KN$20 \mathrm{~L})$ at $873 \mathrm{~K}$. The stress ratio $(R)$ was 0 , the nominal stress $\left(\sigma_{\max }:\right.$ at the specimen center) was $173 \mathrm{MPa}$, the frequency $(f)$ was $6.7 \mathrm{~Hz}$, and the load was a controlled sinusoidal loading pattern. The fatigue test was paused after certain test cycles, and then surface speckles were recorded with the ESPI system (Dr. ETTEMEYER $\mathrm{GmbH} \&$ Co., Q-300) when nominal tensile stresses (increment: $10.4 \mathrm{MPa}$ ) were loaded and unloaded in the order of $0 \mathrm{MPa} \rightarrow 173 \mathrm{MPa} \rightarrow 0 \mathrm{MPa}$ step-by-step.

The schematic illustrations of the ESPI system are shown in Figs.2 and 3. Two illuminated laser beams produce a speckle (Fig.2 (b)) on the specimen surface. The speckle moves (changes) when deformation occurs on the specimen surface. Correlation fringes (Fig.3 (b)) can be produced when speckles before and after the

Received June 14, 2002

Accepted January 6, 2003

Original paper in Japanese was published in Journal of the Society of Materials Science, Japan, Vol. 51, No. 12 (2002) pp. $1417-1422$. 
deformation are interfered. The displacement $(u)$ (Fig.3(c)) of the specimen surface is described in Equation (1) [19, 20],

$$
u=\frac{n \lambda}{2 \sin \frac{\theta}{2}},
$$

where $n$ is the number of the fringe, $\lambda$ is the laser wave length $(750 \mathrm{~nm})$, and $\theta$ is the angle between the two illuminated laser beams. The strain distribution (Fig.3(d)) can be obtained by differentiating the displacement distribution ( Fig.3(c)). The color variations from black to blue to red on the displacement / strain distribution figures mean the displacement / strain values increased. The calibration length to calculate the strains was $0.2 \mathrm{~mm}$ in this work.

The ESPI system (Type Q-300, Dr. ETTEMEYER $\mathrm{GmbH} \& \mathrm{Co}$.) was used, by which a minimum displacement of $0.03 \mu \mathrm{m}$ can be detected. The deformation measurement areas in this work were the $24 \mathrm{~mm} \times 5 \mathrm{~mm}$ center area (Fig.3(a)) at high temperatures, and the $30 \mathrm{~mm} \times 30 \mathrm{~mm}$ area at room temperature. The left side and the right side were defined based on Fig.3 (a) for the two notches. Data processes were carried out using the ISTRA data system (Dr. ETTEMEYER GmbH \& Co.).

The surface and cross-sectional morphologies before and after the fatigue tests were observed with SEM. Specimens were heated with an induction heating system and the temperatures were measured with a radiation thermometer.

\section{RESTULTS AND DISCUSSIONS}

3.1. Strain Values by the Strain Gauge and the ESPI Method

Figure 4 shows strain values measured by the strain

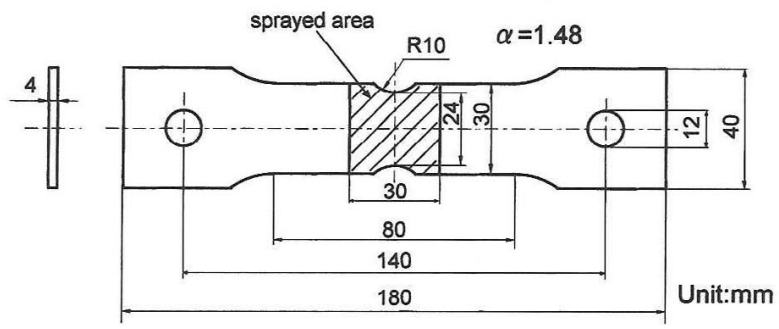

Fig.1. Specimen shape used in test.

Table 1. Atmospheric plasma spraying conditions.

\begin{tabular}{c|c|c|c}
\hline & $\mathrm{Al}_{2} \mathrm{O}_{3}$ ceramics coating & $\mathrm{Ni}-\mathrm{Cr}$ coating \\
\hline Chemical composition $($ wt.\%) & $99.8 \% \mathrm{Al}_{2} \mathrm{O}_{3}$ & $80 \% \mathrm{Ni}, 20 \% \mathrm{Cr}$ \\
\hline \multicolumn{2}{c|}{ Grain size $(\mu \mathrm{m})$} & 20.7 & 70.8 \\
\hline \multicolumn{2}{c|}{ Arc current $(\mathrm{A})$} & 450 & 400 \\
\hline \multicolumn{2}{c|}{ Arc voltage $(\mathrm{V})$} & 45 & 30 \\
\hline \multirow{2}{*}{ Gas } & $\mathrm{Ar}\left(\mathrm{mm}^{3} / \mathrm{s}\right)$ & $2.5 \times 10^{5}$ & $3.3 \times 10^{5}$ \\
\cline { 2 - 4 } & $\mathrm{He}\left(\mathrm{mm}^{3} / \mathrm{s}\right)$ & $8.3 \times 10^{4}$ & \\
\hline \multicolumn{2}{c|}{ Spraying distance $(\mathrm{mm})$} & 100 & 100 \\
\hline \multicolumn{2}{c|}{ Coating thickness $(\mu \mathrm{m})$} & $100 \pm 20$ & $100 \pm 20$ \\
\hline
\end{tabular}

gauge and the ESPI method (calibration length: $5 \mathrm{~mm}$ ) at the same positions of $\mathrm{E}$ and $\mathrm{C}$ on an un-sprayed specimen at room temperature. This result indicates a good correspondence of the strain values measured by the ESPI method with those by the strain gauge.

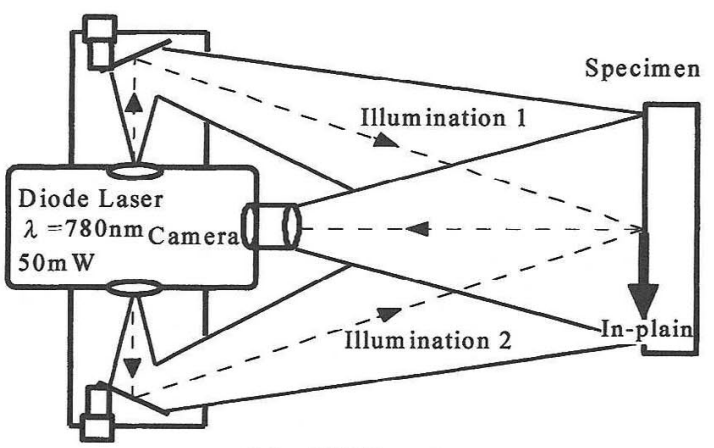

(a) ESPI system

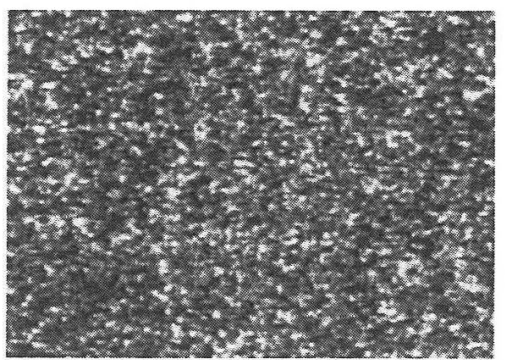

(b) Typical speckle pattern

Fig.2. (a) Schematic illustration of electronic speckle pattern interferometry (ESPI) system and (b) typical speckle pattern.

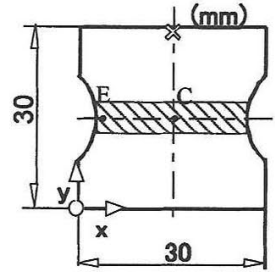

(a)

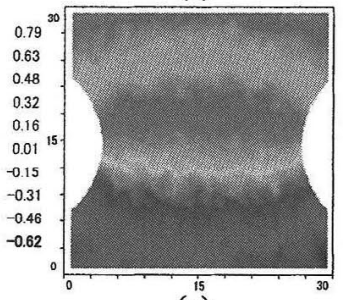

(c)

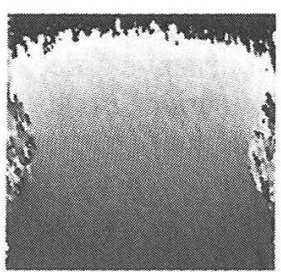

(b)

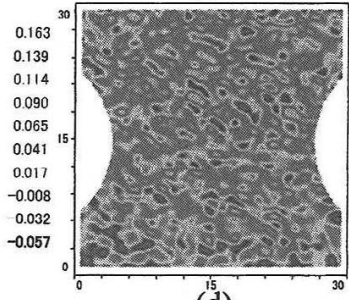

(d)
Fig.3. The measurement coordinate (a), interferometry fringe phase distribution (b), displacement distribution (c) and strain distribution (d) of a SUS304 steel specimen when a nominal tensile stress is loaded from $0 \mathrm{MPa}$ to $10.4 \mathrm{MPa}$ at $293 \mathrm{~K}$. 


\subsection{Deformation Measurement by the ESPI Method at High Temperatures}

Figure 5 shows the strain values of un-sprayed and sprayed specimens, which were heated to $873 \mathrm{~K}$, loaded to $173 \mathrm{MPa}$, and hold for $15 \mathrm{ks}$ in order. The strain changes due to heating for both specimens were much larger than those due to loading and load holding.

Figure 6 shows typical strain values at the centers of the un-sprayed and the sprayed specimens at $N=2$ and $1 \times 10^{5}$ cycles. The maximum strain values were almost the same for both specimens, however, the deformation at $N=2$ cycles was a little larger than that at $N=1 \times 10^{5}$ cycles. Generally, the Young's moduli of thin $\mathrm{Al}_{2} \mathrm{O}_{3}$ and $\mathrm{NiCr}$ spraying coatings are much lower than the sintering types resulting from the un-avoidable holes that exist in them $[5,11]$. Their Young's moduli are also much lower than the SUS304 steel substrate [3]. Accordingly, the restriction effect of coatings on the substrate deformation could be very small, resulting that the deformation of the

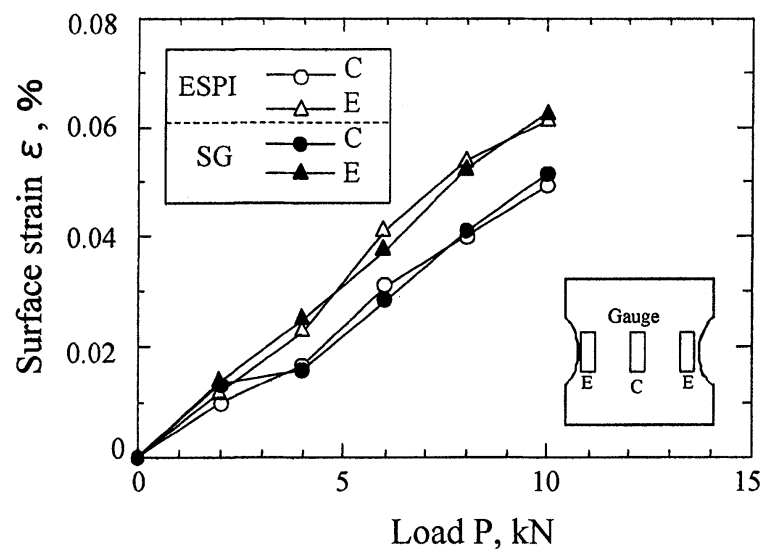

Fig.4. Load-strain curves (gauge length: $5 \mathrm{~mm}$ ) according to the strain gauge (SG) and the ESPI system.

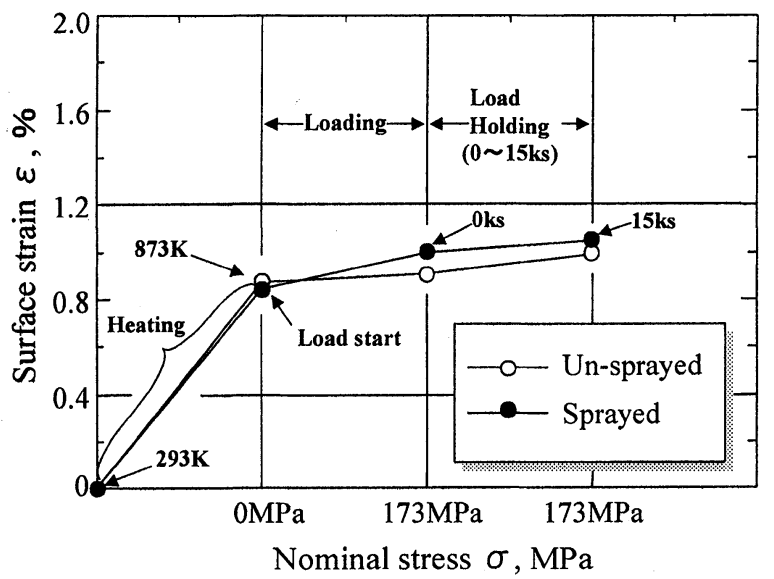

Fig.5. Strain variations measured at the centers of un-sprayed and sprayed specimens during the process of heating (293K-873K), loading (nominal stress $0-173 \mathrm{MPa})$, and holding (0-15ks). thin coatings might be almost associating with or be the same as that of the substrate. The Vickers hardnesses $(9.8 \mathrm{~N}, 15 \mathrm{~s})$ were measured at the center and $1 \mathrm{~mm}$ from the notch root of the substrate before and after $1 \times 10^{5}$ cycles test at $873 \mathrm{~K}$. As a result, the hardness before the test was $H V=226$, and that after $1 \times 10^{5}$ cycles test at $873 \mathrm{~K}$ became $H V=237$ at the center and $H V=260$ near the notch root, indicating that the deformation decrease after $1 \times 10^{5}$ cycles test at $873 \mathrm{~K}$ resulted from the cyclic hardening effect of austenite steel.

\subsection{SEM Observation of Sprayed Specimens after Fatigue Test}

Figure 7 shows surface and cross-sectional morphologies near the notch root of sprayed specimens after 2 and $1 \times 10^{5}$ cycles fatigue test. Surface cracks occurred from the notch root on the $\mathrm{Al}_{2} \mathrm{O}_{3}$ outer coating and stopped at the $\mathrm{NiCr}$ inner coating after 2 cycles test. Although no cracks were observed in the substrate, delamination along the $\mathrm{NiCr} /$ substrate interface was observed and surface cracks prorogated through the $\mathrm{NiCr}$ coating after $1 \times 10^{5}$ cycles test. Cracks and delamination were also observed at the center of the specimen (See position $\mathrm{C}$ in Fig.3 (a)). There were no cracks or delamination observed at $\sigma_{\max }=140 \mathrm{MPa}$ after 2 cycles and $\sigma_{\max }=108 \mathrm{MPa}$ after $1 \times 10^{5}$ cycles.

\subsection{Cracks and Delamination Detection by the ESPI Method}

The stress-strain curves measured at two positions of

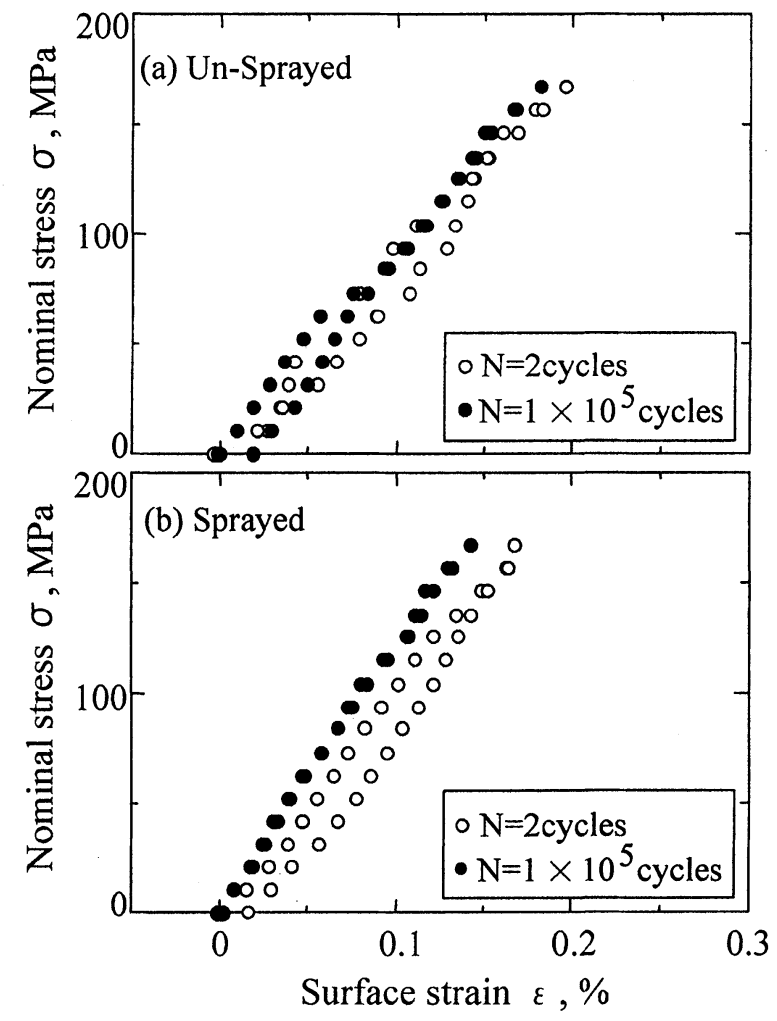

Fig.6. Nominal stress-strain curves measured at the centers of un-sprayed and sprayed specimens at $873 \mathrm{~K}$. 
A and B at $N=1$ cycle test are shown in Fig.8 (a). The strains linearly increased with stress increasing until suddenly becoming much larger when $\sigma=125 \mathrm{MPa}$. According to the SEM observation after $1 \times 10^{5}$ cycles (Fig.8 (b)), separately occurring and then combined cracks were observed at positions $\mathrm{A}$ and $\mathrm{B}$, indicating these cracks were not initiated and continuously propagated near the notch root but from inner defects in the coating. The suddenly occurring strain increase could be attributed to the sudden initiation / opening of cracks

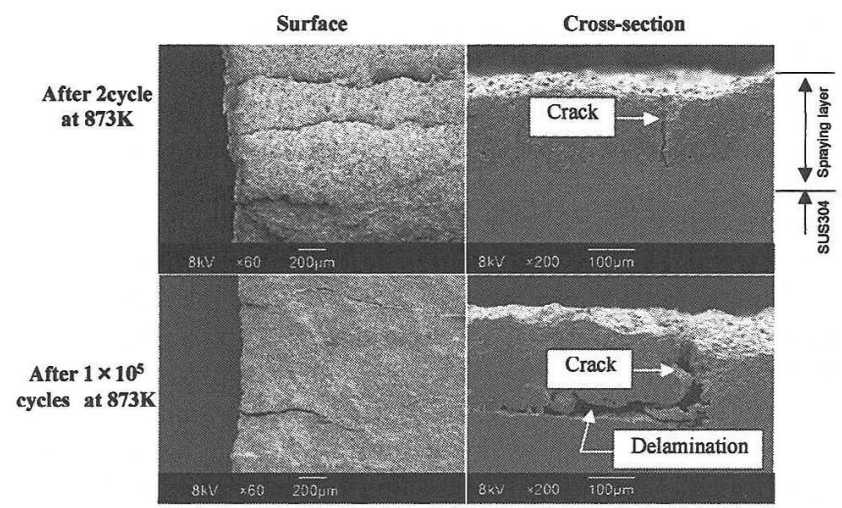

Fig.7. Surface and cross-sectional morphologies near the notch of a sprayed specimen after fatigue test at $873 \mathrm{~K}$.
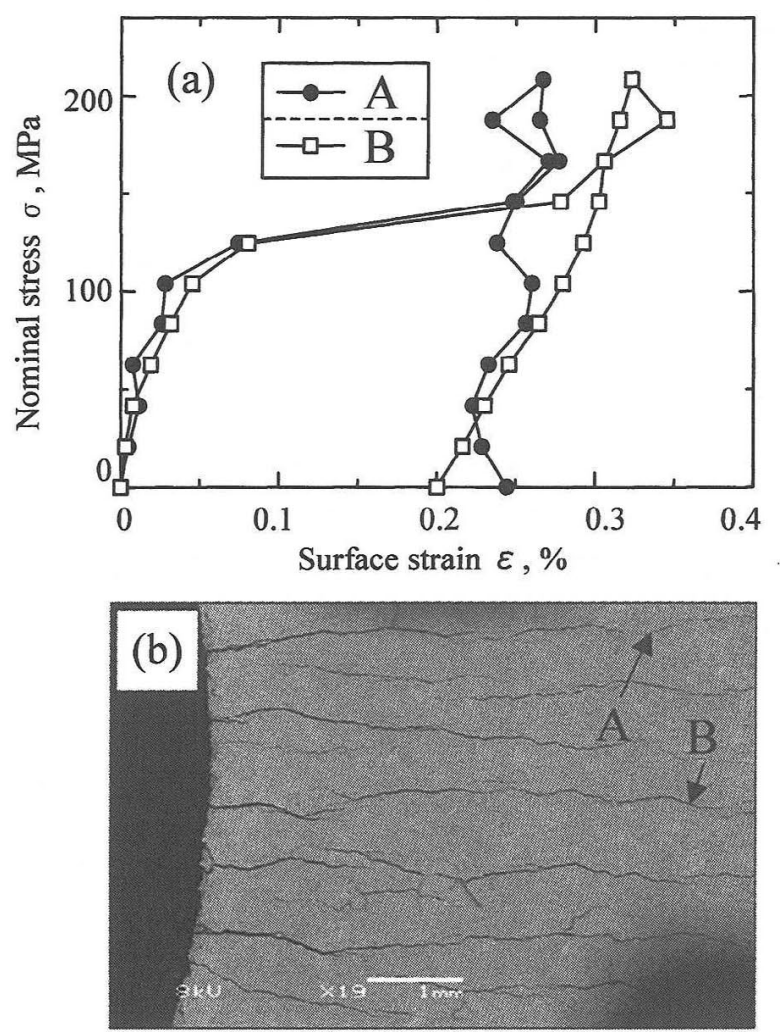

Fig.8. The stress-strain curves (a) at the positions A and B (b) of a sprayed specimen where crack initiation occurred when a nominal stress of $173 \mathrm{MPa}$ was loaded at $873 \mathrm{~K}$. and their combination [22]. The position of crack occurrence during loading might be identified using this method. Moreover, a residual strain of about $0.25 \%$ was due to the residual opening of the cracks.

The identification of cracks using the strain increase phenomenon on surfaces is discussed. Figures 9 (a) and (b) show the displacement and strain distributions on the sprayed specimen surface with long cracks $(>5 \mathrm{~mm})$ when a nominal stress of $104 \mathrm{MPa}$ was loaded. These cracks occurred in the condition $\left(\sigma_{\max }=208 \mathrm{MPa}, T=873 \mathrm{~K}\right)$ for 1cycle test. By comparing the red strain concentration zones in Figs.9 (a) and (b) and the position of each crack in Fig.9(c), their correspondence was clear, i.e., cracks more than $5 \mathrm{~mm}$ can be detected using the ESPI method.
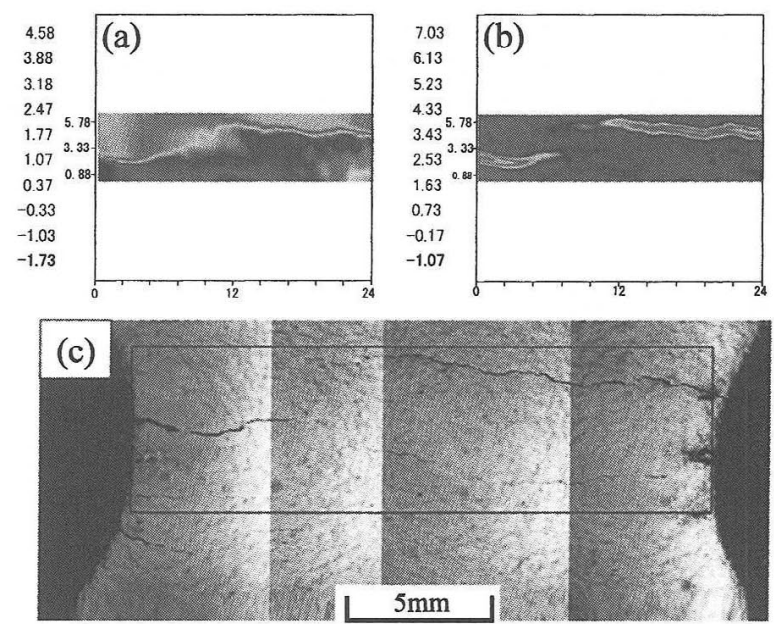

Fig.9. The distributions of displacement (a) and strain (b) on a sprayed specimen surface (c) with long cracks when a nominal stress of $104 \mathrm{MPa}$ was loaded at $873 \mathrm{~K}$.

Figure 10 shows one result of the displacement and strain distributions $\left(N=1 \times 10^{5}\right.$ cycles $)$ and surface / cross-sectional morphologies after $1 \times 10^{5}$ cycles test. The strain concentration zones on the left side were closely corresponding to the position of each crack (Figs. $\left(c_{1}\right)$ and $\left(c_{2}\right)$ ), while cracks cannot be observed on the right side (Figs. $\left(\mathrm{d}_{1}\right), \mathrm{Al}_{2} \mathrm{O}_{3}$ side: $\left.\mathrm{A} . \mathrm{S}\right)$. However, cracks (Figs. $\left(d_{2}\right)$ and $\left(d_{3}\right)$ ) on the $\mathrm{Ni}-\mathrm{Cr}$ layer were observed and corresponded closely to the position of the strain concentration zone on the right $\mathrm{NiCr}$ side (N.S) after the coating delaminated with quick cooling. Accordingly, short cracks as small as $500 \mu \mathrm{m}$ and inner cracks could also be detected using the ESPI method.

Figure 11 shows another result of the strain distribution at $\mathrm{N}=1$ cycle (a), $\mathrm{N}=2$ cycles (b), $\mathrm{N}=1 \times 10^{5}$ cycles (c), and surface morphologies (d) (e) and (f). Fig.11 (g) is the cross-sectional morphology near the cracks (1) and (2) in Fig.11(f), which is observed from the right side of the specimen. Although the deformation was unstable during the initial load, it became stable and the strain concentration zones appeared near the notch root from $N=2$ cylce test. However, the strain decrease at the position A with increasing cycles was clear. Their 
stress - strain curves measured by ESPI at the position A (Fig. 11(a)) are shown in Fig.12. Although a maximum strain of about $0.25 \%$ occurred at $N=1$ cycle, it disappeared from $N=100$ cycles. On the other hand, the local delamination after $1 \times 10^{5}$ cycles test was confirmed near the position A (Figs.11(f) and (g)), indicating a large decrease of the surface strain with cycles was a result of the local delamination of the spraying coating.

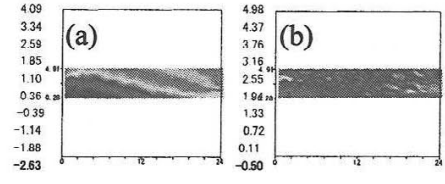

(c) Left

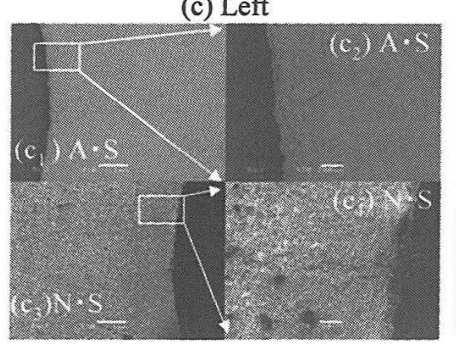

(d) Right

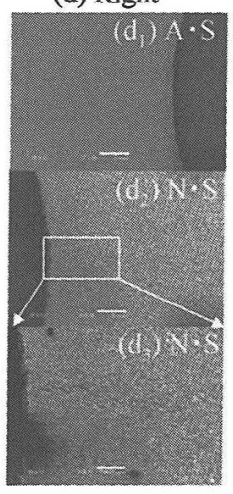

Fig.10. The distributions of displacement (a) and strain (b) on a sprayed specimen surface, where no cracks exist on the right $\mathrm{Al}_{2} \mathrm{O}_{3}$ side $\left(\mathrm{A} \cdot \mathrm{S}: \mathrm{d}_{1}\right)$, but small cracks exist on the left $\mathrm{Al}_{2} \mathrm{O}_{3}$ side $\left(\mathrm{c}_{1}, \mathrm{c}_{2}\right)$ and the NiCr side $\left(\mathrm{N} \cdot \mathrm{S}: \mathrm{c}_{3}\right.$, $\left.c_{4}\right)$ and the right $\mathrm{NiCr}$ side $\left(\mathrm{d}_{2}, \mathrm{~d}_{3}\right)$ of the spraying film when a nominal stress of $173 \mathrm{MPa}$ was loaded at $873 \mathrm{~K}$.

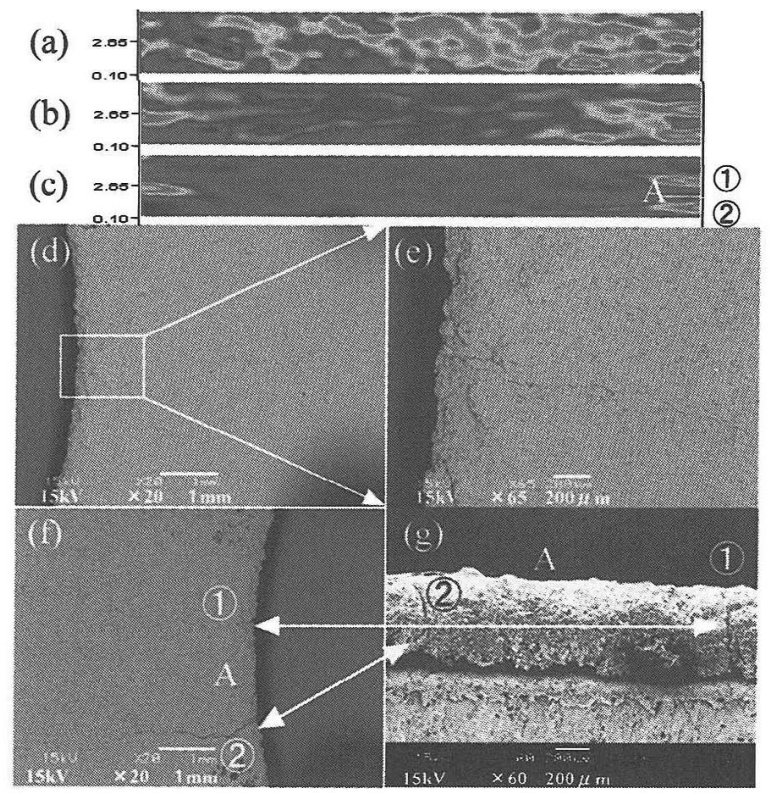

Fig.11. The correspondence of strain concentration (a: 1 cycle, b: 2 cycles, c: $1 \times 10^{5}$ cycles) and cracks (d, e: left side surface, $f$ : right side surface, $g$ : right side cross-section) on a sprayed film when a nominal stress of $173 \mathrm{MPa}$ was loaded at $873 \mathrm{~K}$.
According to the above results, the initiation and existence of cracking/delamination of the sprayed coatings during the fatigue test can be nondestructively detected by analyzing the strain concentration or decrease using the ESPI method. Hereafter, both spraying materials and composite materials will be applied to further confirm the advantage of ESPI method. Moreover, more details of high temperature fatigue deformation behavior of sprayed materials under various stress conditions are being planned in order to make the best uses of the ESPI method, which can be applicable for in-situ detection of cracks and delamination of sprayed materials.

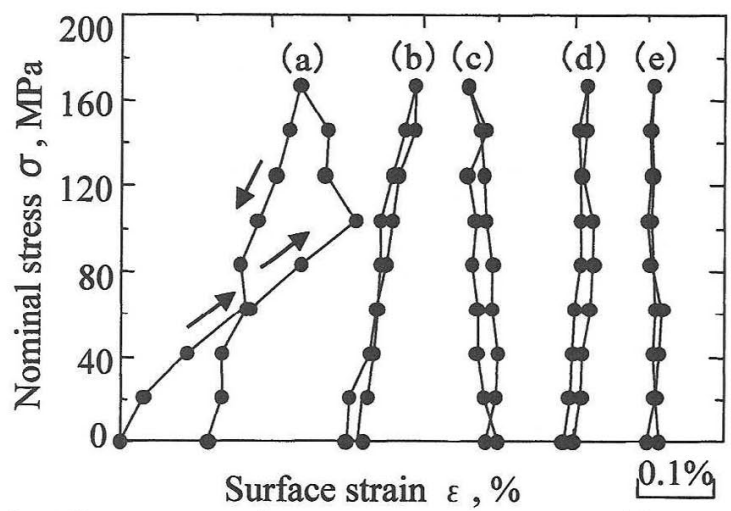

Fig.12. The stress-strain curves measured at position $\mathrm{A}$ in Fig.11(c) with the increase of fatigue cycles. (a) $\mathrm{N}=1$ cycle, (b) $\mathrm{N}=2$ cycles, (c) $\mathrm{N}=100$ cycles, (d) $\mathrm{N}=1 \times 10^{4}$ cycles and (e) $\mathrm{N}=1 \times 10^{5}$ cycles.

\section{CONCLUSIONS}

Fatigue tests were carried out on $\mathrm{Al}_{2} \mathrm{O}_{3} / \mathrm{NiCr}$ thermally sprayed SUS304 steel specimens at $873 \mathrm{~K}$. The influence of cracking and delamination on the surface deformation was investigated by the electronic speckle pattern interferometry (ESPI) method. The results obtained are as following.

(1) The strain values measured by the ESPI method were almost the same as those measured by the strain gauge at room temperature.

(2) The surface deformation was almost the same for un-sprayed and sprayed specimens, indicating the deformation of coatings is associated with the substrate. The maximum strain at $N=1 \times 10^{5}$ cycles was a little lower than that at $N=2$ cycles.

(2) Cracks in the $\mathrm{Al}_{2} \mathrm{O}_{3}$ coating occurred but had stopped at the $\mathrm{NiCr}$ coating after 2 cycles fatigue test when $\sigma_{\max }$ was $173 \mathrm{MPa}$ at $873 \mathrm{~K}(R=0)$. Cracks propagated through the $\mathrm{NiCr}$ coating and caused delamination along the $\mathrm{NiCr} /$ substrate interface after $1 \times 10^{5}$ cycles test.

(3) The strain concentration and decrease with cyclic stress were observed by the ESPI method.

\section{REFERENCES}

1. K.Kojima, J. Surface Finishing Soc., Japan, 41 (1990) 988 (in Japanese).

2. M.Kido, R.Wang, S.Nakamura, M.Takeda, M.Yamazaki and 


\section{$\underline{\text { Rongguang WANG, Tarou ToKUDA and Mitsuo KIDO }}$}

T.Tokuda, J. Soc. Mat. Sci. , Japan, 51 (2002), 1417 (in Japanese).

3. I.Nishikawa, K.Ogura, M.Yamagami and K.Kuwayama, J.Soc. Mat. Sci., Japan, 43 (1994) 1290 (in Japanese).

4. H.Waki, K.Ogura and I.Nishikawa, JSME International Journal, Series A, 44 (2001) 374.

5. K.Ogura, I.Nishikawa, H.Waki, Proc. $48^{\text {th }}$ J. Soc. Mat. Sci. , Japan, (1995) 131 (in Japanese).

6. H.Waki, M.Nishii, K.Ogura and I.Nishikawa, Trans. Jpn. Soc. Mech. Eng, Series A, 66 (2000) 1520 (in Japanese).

7. H.Waki, K.Ogura I.Nishikawa, H.Nagamura and M.Nishii, Trans. Jpn. Soc. Mech. Eng, Series A, 66 (2001) 1148 (in Japanese)

8. A.Ibrahim and C.C.Berndt: J. Mat. Sci., 33 (1998) 3095.

9. Y.Itoh, M.Satoh, Y.Harada and J.Takeuchi, J. Soc. Mat. Sci., Japan, 44 (1995) 1361 (in Japanese).

10. M.Takeda, T. Okabe, M.Kido and Y.Harada, J. Japan Thermal Spraying Society, 38 (2001) 58 (in Japanese)

11. T.Shiraishi, H.Ogiyama, H.Tsukuda and Y.Soyama, J. Hig. Tem. Soc., 17 (1991) 34 (in Japanese).

12. T.Ogawa, J. Japan Thermal Spraying Society, 35 (1998)
307 (in Japanese).

13. M.Ohki, T.Hwu, Y.Mutoh, H.Kita and Y.Unno, J. Japan Thermal Spraying Society, 36 (1999) 12 (in Japanese).

14. J.Oh, J.Komotori and M.Shimizu, J. Japan Thermal Spraying Society, 37 (2000) 166 (in Japanese).

15. J.Hwang, T.Ogawa, K.Tokaji, T.Ejima, Y.Hobayashi and Y.Harada, J. Soc. Mat. Sci. , Japan, 45 (1996) 927 (in Japanese).

16. H.Suzuki, T.Ueki and M.Fukumaoto, Trans. Jpn. Soc. Mech. Eng, Series A, 57 (1991) 1062 (in Japanese).

17. D.Zhang, M.Kato and K.Nakasa, J. Soc. Mat. Sci. , Japan, 48 (1999) 1065 (in Japanese).

18. A.J.Moore and J.R.Tyrer, J. Strain Analysis, 29 (1994) 257.

19. S.Toyooka, Metals \& Technology, 70 (2000) 869 (in Japanese).

20 K.Kim and M.Murozono, Trans. Jpn. Soc. Mech. Eng., Series A, 60 (1994) 2567 (in Japanese).

21. S. Dilhaire, S.Jorez, A. Cornet, E. Schaub and W. Claeys, Microelectronics Reliability, 39 (1999) 981.

22 T.Torii, K.Honda, T.Fujibayashi and T.Hatano, Trans. Jpn. Soc. Mech. Eng, Series A, 55 (1989) 1525 (in Japanese). 